\title{
Impact of maternal obesity on obstetric outcome in a rural population in Pondicherry
}

\author{
Anitha Vijay*, Gayathri Maran, Vijaya Koothan
}

Department of Obstetrics \& Gynaecology, Aarupadai Veedu Medical College \& Hospital, Pondicherry, India

Received: 01 April 2015

Accepted: 18 April 2015

\section{*Correspondence:}

Dr. Anitha Vijay,

E-mail: dranithav_83@yahoo.co.in

Copyright: $\odot$ the author(s), publisher and licensee Medip Academy. This is an open-access article distributed under the terms of the Creative Commons Attribution Non-Commercial License, which permits unrestricted non-commercial use, distribution, and reproduction in any medium, provided the original work is properly cited.

\begin{abstract}
Background: The aim of the current study is to assess the impact of maternal obesity on maternal and fetal outcome in a rural setup

Methods: This prospective comparative study was carried out in a tertiary health care setup in rural south India. The study enrolled hundred pregnant women who were divided into two groups based on their body mass index, as obese $(\mathrm{BMI} \geq 30)$ and non-obese (BMI <30) categories. Maternal and fetal outcomes were studied. Data was analysed for significance with Chi-square test.

Results: There were significant associations between maternal obesity and adverse pregnancy outcomes such as pregnancy induced hypertension $(P=0.0145)$, gestational diabetes $(P=0.0285)$, induction of labour $(P=0.05)$, instrumental delivery $(P=0.049)$, caesarean deliveries $(P=0.0005)$ and shoulder dystocia $(P=0.0451)$. Post-partum complications like atonic post-partum hemorrhage $(\mathrm{P}=0.0359)$ and puerperal sepsis $(\mathrm{P}=0.00139)$ were more in obese mothers. Neonatal complications like macrosomia $(P=0.0056)$, low APGAR $(P=0.0147)$, intensive care admissions $(P=0.0061)$ and perinatal deaths $(P=0.045)$ were also found to be significantly more common in babies born to obese mothers. No significant associations were seen in occurrence of malpresentations, failed induction, nonprogress of labour and other complications.

Conclusions: Obese women are at increased risk of both maternal and fetal complications even in a rural population where it is thought to be less prevalent when compared to urban population. As obesity is a preventable condition, awareness and proper counseling regarding the hazards of obesity is becoming highly necessary.
\end{abstract}

Keywords: BMI, Obesity, Obstetric outcome, Rural population

\section{INTRODUCTION}

Obesity has become a worldwide phenomenon cutting across regional and economic barriers. WHO describes obesity as "one of the most blatantly visible, yet most neglected public health problems that threaten to overwhelm both more and less developed countries". Obesity is a "killer disease" at par with HIV and malnutrition according to WHO. The WHO estimates that in 2014, approximately 1.9 billion people worldwide were overweight and atleast 600 million adults were obese. $^{2}$
The prevalence of obesity is increasing steadily even in developing countries as economic prosperity has increased. In developing countries like India, overweight and obesity often co-exist with undernutrition. ${ }^{3}$ Comparison of two major studies conducted by NFHS-2 (National Family Health Survey) in 1998-1999 and NFHS-3 in 2005-2006 shows that the prevalence of obesity among Indian women has elevated from 10.6 to $12.6 \%{ }^{4}$

The Body Mass Index (BMI) is the most commonly used measure for monitoring prevalence of obesity at 
population level. BMI or Quetelet index is a measure of human body fat based on an individual's weight and height which was devised between 1830 and 1850 by the Belgian polymath Adolphe Quetelet during the course of developing "social physics". $5 \mathrm{BMI} \geq 30$ is defined as obesity according to WHO \& NIH. ${ }^{6}$

Antenatally, obesity has been associated with an increase in the risk of abortion, gestational diabetes, gestational hypertension and pre eclmapsia. ${ }^{7}$ It has also been associated with prolonged pregnancies, prolonged labour, increased rates of caesarean deliveries, increased incidence of post natal infections with prolonged hospital stay. $^{8,9}$

Obesity is also associated with a higher risk of adverse neonatal outcomes including still births, congenital anomalies, neonatal intensive care admissions and perinatal mortality rates. ${ }^{10,11}$ Furthermore, long term studies demonstrate that having an obese mother increases the risk of child growing up to be obese themselves. ${ }^{12}$ Thus, the need to study the impact of maternal obesity on the long term health of the society as a whole is all the more important.

The effect of low maternal weight and anemia on obstetric outcome is already well established in various studies. With increasing prevalence of overweight and obesity in India, the need to determine its effect on maternal and fetal outcome is alarmingly increasing. There are some studies regarding this in western countries but very few in developing countries. This study aims to highlight the impact of maternal obesity on maternal and fetal outcome in a rural set up.

\section{METHODS}

This was a prospective comparative study conducted over a period of six months from July 2014 to December 2014 in the department of obstetrics and gynaecology, Aarupadai Veedu Medical College \& Hospital, Pondicherry. Sample size was 100. 50 in each of the two groups based on maternal BMI as obese and non-obese categories. Study population included all primigravida with singleton pregnancy coming for admission to labour room at the time of delivery.

\section{Inclusion criteria}

1. Primigravida with singleton pregnancy

2. Gestational age more than 28 weeks

\section{Exclusion criteria}

1. Multiple pregnancy

2. Multigravida

3. Known diabetic

4. Known hypertensive

5. Known medical disorders (renal diseases, thyroid disorders, heart disease, epilepsy, bronchial asthma)
After informed written consent, pregnant women satisfying the criteria were included in the study. A detailed history regarding present and past complaints, menstrual, obstetric and family history was taken. Detailed clinical examination including general, obstetric examination was performed. Per vaginal examination and Bishop's scoring was done. All routine antenatal investigations and other investigations necessary to rule out medical disorders were done.

Weight was measured in kilograms, without shoes, wearing light clothes. Height in metres was measured using stadiometer. The patients were made to stand erect on the floor barefoot with both ankles together and parallel to each other. The head of the patient was held in such a position that the line joining the tragus and outer canthus of eye were in a horizontal plane (Frankfurt's plane), with the individual standing straight next to wall with heels, buttocks, shoulder and occiput touching the wall.

The data were used to calculate Quetelet index or Body Mass Index (BMI) using formula, BMI = Weight in $\mathrm{kg} / \mathrm{height}^{2}$ in metres. Then patients were divided into two groups:

\section{1. $\quad \mathrm{BMI} \geq 30$ (subjects) \\ 2. $\mathrm{BMI}<30$ (controls)}

Available standard care was provided to all of them. Spontaneous labour was awaited in all of the cases. Induction of labour and caesarean section was performed only for maternal or fetal indication. Babies were assessed by APGAR score at 1 and 5 minutes of birth. Birth weight, admission to neonatal ward was recorded and fetal outcome noted.

Maternal outcome variables studied include gestational diabetes, gestational hypertension, malpresentation, intra uterine growth restriction, induction of labour, nonprogress of labour, fetal distress, instrumental delivery, LSCS and its related complications, shoulder dystocia, post-partum hemorrhage and puerperal sepsis. Fetal outcome variables studied were birth weight, low APGAR, neonatal intensive care admissions and perinatal death. In this study, failed induction was defined as failure to establish labour after insertion of two vagnial PGe2 gel (1-2 mg) at 6 hourly intervals. Non progress of labour was defined as dilatation less than $1 \mathrm{~cm} /$ hour in the active phase of labour. Macrosomia was defined as birth weight more than $4 \mathrm{~kg}$. Results were analysed by using chi-square test with probability $\mathrm{P} \leq 0.05$ taken as significant.

\section{RESULTS}

Body mass index was calculated for 100 pregnant women, fulfilling the inclusion criteria, who were admitted to labour room and then they were divided into two groups as obese and non-obese. Various maternal 
and fetal outcome variables were studied and statistical analysis was done using Chi-square test. Statistical significances were assumed with a probability error $\mathrm{P}<0.05$. Taken together, the results are presented in tables.

Table 1: Ante partum complications and its relation with BMI.

\begin{tabular}{|c|c|c|c|}
\hline \multirow[t]{2}{*}{ Complication } & $\begin{array}{l}\text { Subjects } \\
(\mathrm{BMI} \geq \mathbf{3 0})\end{array}$ & $\begin{array}{l}\text { Controls } \\
(\text { BMI <30) }\end{array}$ & \multirow[t]{2}{*}{ P value } \\
\hline & No (\%) & No $(\%)$ & \\
\hline PIH & $18(36)$ & $5(10)$ & 0.0145 \\
\hline GDM & $4(8)$ & $1(2)$ & 0.0285 \\
\hline Malpresentations & $3(6)$ & $1(2)$ & 0.234 \\
\hline IUGR & $3(6)$ & $2(4)$ & 0.0913 \\
\hline
\end{tabular}

Table 1 shows that out of a total of 50 pregnancies in each group, only $44 \%$ of patients in the obese category were without complications in comparison with the nonobese group were $82 \%$ of them were free of complications. Preeclampsia complicated $36 \%$ pregnancies in $\mathrm{BMI} \geq 30$ and $10 \%$ in $\mathrm{BMI}<30$. The difference was statistically significant with a $\mathrm{P}$ value of 0.0145 . There was a statistically significant increase in the incidence of GDM in obese women with BMI $\geq 30$ in comparison with non-obese with a $\mathrm{P}$ value of 0.0285 . Other antenatal complications studied like malpresentations and IUGR were also found to be more common in subjects but the difference was not statistically significant.

Table 2: Mode of termination of pregnancy and its relation with BMI.

\begin{tabular}{|llll|} 
& $\begin{array}{l}\text { Subjects } \\
(\mathrm{BMI} \geq 30)\end{array}$ & $\begin{array}{l}\text { Controls } \\
(\mathrm{BMI}<30)\end{array}$ & P value \\
& $\mathbf{N o}(\boldsymbol{\%})$ & $\mathbf{N o}(\%)$ & \\
\hline Spontaneous labour & $10(20)$ & $25(50)$ & 0.015 \\
\hline Induced labour & $15(30)$ & $10(20)$ & 0.05 \\
\hline Instrumental delivery & $3(6)$ & $2(4)$ & 0.049 \\
\hline LSCS & $22(44)$ & $13(26)$ & 0.0005 \\
\hline
\end{tabular}

The frequency of spontaneous labour was more in the BMI <30 group $25(50 \%)$ and it was $10(20 \%)$ in the BMI $\geq 30$ group with a statistically significant difference ( $P$ value 0.015 ). The need for induction of labour was high in obese category $15(30 \%)$ in comparison with nonobese category $10(20 \%)$ and the difference was statistically significant with a $\mathrm{P}$ value $0.05 .3(6 \%)$ women in the BMI $\geq 30$ group required instrumental delivery whereas $2(4 \%)$ in BMI $<30$ group with a statistically significant $\mathrm{P}$ value of 0.049 . The incidence of elective and emergency caesarean sections were higher in obese women with $22(44 \%)$ of them landing up in caesarean when compared with $13(26 \%)$ in non-obese group. The difference was statistically significant ( $\mathrm{P}$ value 0.0005$)$.
Table 3: Intra partum complications and its relation with BMI.

\begin{tabular}{|llll|}
\hline Complication & $\begin{array}{l}\text { Subjects } \\
(\text { BMI } \geq 30)\end{array}$ & $\begin{array}{l}\text { Controls } \\
(\mathbf{B M I}<30)\end{array}$ & $\begin{array}{l}\text { P } \\
\text { value }\end{array}$ \\
\cline { 1 - 3 } & $\mathbf{N o ( \% )}$ & $\mathbf{N o}(\%)$ & \\
\hline Failed induction & $3(6)$ & $1(2)$ & 0.4369 \\
\hline Non progress of labour & $1(2)$ & $1(2)$ & 0.863 \\
\hline Fetal distress & $1(2)$ & $1(2)$ & 0.456 \\
\hline Shoulder dystocia & $3(6)$ & $0(0)$ & 0.0451 \\
\hline
\end{tabular}

According to Table 3, the frequency of failed induction was more in the subjects than the controls but the difference was not statistically significant. There was no difference in the incidence of non-progress of labour and fetal distress. But there were 3 cases of shoulder dystocia in the obese category with nil in the non-obese clearly indicating that obese women are more prone for shoulder dystocia and its related complications (P value 0.0451 ).

Table 4: Post-partum complications and its relation with BMI.

\begin{tabular}{|llll|} 
Complication & $\begin{array}{l}\text { Subjects } \\
(\mathrm{BMI} \geq 30)\end{array}$ & $\begin{array}{l}\text { Controls } \\
(\mathrm{BMI}<30)\end{array}$ & P value \\
& No(\%) & No(\%) & \\
\hline Atonic PPH & $3(6)$ & $1(2)$ & 0.0359 \\
\hline Traumatic PPH & $4(8)$ & $1(2)$ & 0.858 \\
\hline Puerperal sepsis & $5(10)$ & $2(4)$ & 0.00139 \\
\hline
\end{tabular}

The incidence of atonic post-partum hemorrhage was higher in the subjects with a statistically significant difference $\mathrm{P}$ value of 0.0359 . Traumatic post-partum hemorrhage complicated $4(8 \%)$ of cases in the BMI $\geq 30$ category and $1(2 \%)$ case in BMI $<30$ but the difference was not statistically significant ( $\mathrm{P}$ value 0.858 ). The incidence of puerperal sepsis was significantly high in subjects than controls with a $\mathrm{P}$ value 0.00139 .

Table 5: Neonatal complications and its relation with BMI.

\begin{tabular}{|c|c|c|c|}
\hline \multirow[t]{2}{*}{ Complication } & $\begin{array}{l}\text { Subjects } \\
(\mathrm{BMI} \geq 30)\end{array}$ & $\begin{array}{l}\text { Controls } \\
(\mathrm{BMI}<\mathbf{3 0})\end{array}$ & \multirow[t]{2}{*}{ P value } \\
\hline & No $(\%)$ & No $(\%)$ & \\
\hline Low birth weight & $3(6)$ & $2(4)$ & 0.1274 \\
\hline Macrosomia & $8(16)$ & $1(2)$ & 0.0056 \\
\hline Low APGAR & $7(14)$ & $3(6)$ & 0.0147 \\
\hline NICU admissions & $10(20)$ & $2(4)$ & 0.0061 \\
\hline Perinatal death & $1(2)$ & $0(0)$ & 0.045 \\
\hline
\end{tabular}

Table 5 indicates that babies with birth weight more than $4 \mathrm{~kg}$ termed as macrosomic babies were more common with $\mathrm{BMI} \geq 30$ occurring in $8(16 \%)$ mothers whereas only $1(2 \%)$ case in BMI $<30$ group with a statistically significant $\mathrm{P}$ value of 0.0056 . There was no significant difference in the incidence of low birth weight in both the groups. Low APGAR scores at birth and the frequency of neonatal intensive care admissions were also higher in the 
subjects when compared to controls with a statistically significant difference as shown in the table. There was 1 ( $2 \%$ ) perinatal death in $\mathrm{BMI} \geq 30$ group whereas there was no perinatal death in BMI $<30$ group ( $\mathrm{P}$ value 0.045 ).

\section{DISCUSSION}

Obesity has reached epidemic proportions in India in the $21^{\text {st }}$ century, affecting $5 \%$ of the country's population. ${ }^{13}$ Obesity initially thought to be a problem of urban population due to their life style and food habits is now seen commonly even in rural population where health problems related to under nutrition is still a major concern. Thus, India faces a double burden with under nutrition or anemia in one hand and overweight and obesity on other hand. ${ }^{14}$ There are various studies on the effect of anemia on obstetric outcome in rural population. Hence there is an urgent need of studies to determine the impact of maternal obesity on feto-maternal outcome in such rural areas.

Body Mass Index (BMI) provides a more accurate measure of total body fat compared with the assessment of body weight alone. ${ }^{15}$ As BMI is derived from simple measurements of height and weight, it is clearly inexpensive and hence can be used in a study conducted in a rural population. Therefore, taking BMI $\geq 30$ as obesity according to WHO criteria, this study was carried out to assess the effect of maternal obesity on obstetric outcome.

A strong association between increasing BMI and preeclampsia has been found in our study. There are many reports suggesting an increased risk of pregnancy induced hypertension in obese pregnant women. Brien et al. in their meta-analysis of thirteen cohort studies, comprising 1.4 million women, reported that the risk of preeclampsia typically doubled with each $5-7 \mathrm{~kg} / \mathrm{m}^{2}$ increase in maternal BMI. ${ }^{4}$

Results of our study show that there is a significant relationship between maternal obesity and GDM. There are contradictions in this aspect with certain studies showing that obesity without other metabolic problems do not increase the risk of GDM. ${ }^{16}$ But Weiss et al. in their recent meta-analysis of 20 studies demonstrated that the Odds Ratio of developing GDM were 2.14, 3.56 and 8.56 among overweight, obese and severely obese compared with normal weight pregnant women, respectively indicating that high maternal weight is associated with a substantially higher risk of GDM. ${ }^{17}$ There was a positive association between maternal BMI and malpresentations probably due to abdominal wall laxity. The incidence of growth restricted babies was also higher, but not statistically significant.

There are various reports showing the increased prevalence of interventions like induced labour, caesarean delivery and instrumental delivery in obese pregnant women. ${ }^{18}$ Our study also showed a similar association as obese women are more likely to have induction of labour due to various antenatal complications and postdatism. Caesarean rates are also increased due to various conditions like failed induction, non-progress of labor, macrosomia, fetal distress and more recently caesarean delivery on maternal request. There were 3 cases of shoulder dystocia in our study which is a known complication of increased maternal BMI with one baby developing a brachial plexus palsy needing an intensive care admission.

There is a linear increase in maternal blood loss at delivery with increasing weight of pregnant women in our study in accordance with various previous reports. ${ }^{19}$ There is an increased prevalence of puerperal sepsis due to various causes like wound infection, genitor-urinary tract infections and associated morbidity according to our study. Paiva and colleagues also observed that maternal obesity during late pregnancy is independently associated with postpartum infectious complications. ${ }^{20}$

Various studies have found an association of low apgar score at birth, neonatal admissions and increased incidence of perinatal deaths among obese pregnant women which was comparable with our findings. ${ }^{21}$ The impact of abnormal body habitus on birth weight of the baby grows as the maternal BMI increases according to various studies. ${ }^{22}$ The findings in our study showing the increased incidence of macrosomia in obese women was consistent with these studies.

\section{CONCLUSION}

As a conclusion, our study demonstrated the detrimental impact of an increased maternal BMI on maternal and fetal pregnancy outcome in a rural population from south India. With recent studies showing a decline in the urbanrural divide with regard to lifestyle related diseases like obesity, by creating awareness amongst the women, preconception counseling and increasing their accessibility to medical services, maternal and perinatal morbidity and mortality can be minimized. Preconception weight loss and limited pregnancy weight gain can be helpful in achieving the goal we all strive for, a healthy mother and a healthy baby.

\section{Funding: No funding sources \\ Conflict of interest: None declared \\ Ethical approval: Not required}

\section{REFERENCES}

1. James WPT. WHO recognition of the global obesity epidemic. Int J Obes. 2008;32(7):20-6.

2. World Health Organization. Obesity and overweight. Fact sheet N 311, January 2015. Available at: http://www.who.int/mediacentre/factsheets/fs311/en/

3. Mendez MA, Monterio CA, Popkin BM. Overweight exceeds underweight among women in most 
developing countries. Am J Clin Nutr. 2005;81:71421

4. Garg C, Khan SA, Ansari SH, Garg M. Prevalence of obesity in Indian women. Obes Rev. 2010;11(2):1058

5. Eknoyan Garabed. Adolphe Quetelet. (1796-1874) the average man and indices of obesity. Nephrol Dial Transplant. 2008;23(1):47-51.

6. National Institutes of Health. Clinical guidelines on the identification, evaluation, and treatment of overweight and obesity in adults: The evidence report. In: NIH, eds. National Heart, Lung, and Blood Institute. India: NIH Publication No. 98-4083; September 1998.

7. O Brien TE, Ray JG, Chan WS. Maternal body mass index and risk of preeclampsia. A systematic review. Epidemiology. 2003;14:368-74.

8. Sahu MT, Agarwal A, Das V, Pandey A. Impact of maternal body mass index on obstetric outcome. J Obstet Gynaecol Res. 2007;33(5):655-9.

9. Marie I, Cedergren M. Maternal morbid obesity and the risk of adverse pregnancy outcome. Obstet Gynecol. 2004;103(2):219-24.

10. Kabiru W, Raynor BD. Obstetric outcomes associated with increase in BMI category during pregnancy. Am J Obstet Gynaecol. 2004;191(3):92832.

11. Callaway LK, Prins JB, Chang AM, McIntyre HD. The prevalence and impact of overweight and obesity in an Australian obstetric population. Med J Aust. 2006;184(2):56-9.

12. Deierlein AL, Siega-Riz AM, Adair LS, Herring AH. Effects of pre-pregnancy body mass index and gestational weight gain on infant anthropometric outcomes. J Paediatr. 2011;158(2):221-6.

13. IIPS. National family health survey (NFHS-3), 200506, India, 2007. Available at: http://www.rchiips.org/nfhs/nfhs3.shtml.

14. Misra A, Pandey RM, Devi JR, Sharma R, Vikram NK, Khanna N. High prevalence of diabetes, obesity and dyslipidemia in urban slum population in northern India. Int $\mathbf{J}$ Obes Relat Metab Disord. 2001;25(11):1722-9.

15. Heymsfield SB, Allison DB, Pierson RN Jr. Assessment of human body composition. In: Heymsfield SB, Allison DB, Pierson RN Jr., eds. Handbook of Assessment Methods for Eating Behaviors and Weight Related Problems. Measures, Theory and Research. 1st ed. New Delhi, India: Sage Publications; 1995: 515-560.

16. Kongubol A, Phupong V. Prepregnacy obesity and the risk of gestational diabetes mellitus. BMC Pregnancy Childbirth. 2011;11:59-65.

17. Chu SY, Callaghan WM, Kim SY, Schmid CH. Maternal obesity and risk of gestational diabetes mellitus. Diabetes Care. 2007;30(8):2070-6.

18. Weiss JL, Malone FD, Emig D. Obesity, obstetric complications and caesarean delivery rate - a population based screening study. Am J Obstet Gynecol. 2004;190(4):1091-7.

19. Sebire NJ, Jolly M, Harris JP, Wadsworth J. Maternal obesity and pregnancy outcome: a study of 287213 pregnancies in London. Int J Obes Relat Metab Disord. 2001;25:1175-82.

20. Paiva LV, Nomura RM, Dias MC, Zugaib M. Maternal obesity in high-risk pregnancies and postpartum infectious complications. Rev Assoc Med Bras. 2012;58(4):453-8.

21. Wolfe H. High prepregnancy body mass index: a maternal-fetal risk factor. $\mathrm{N}$ Engl $\mathrm{J}$ Med. 1998;338:191-2.

22. Hugh ME, Brian M, Patrick MC. The influence of diabetes and obesity on the prevalence of macrosomia. Am J Obstet Gynaecol. 2004;191(3):964-8.

DOI: $10.18203 / 2320-1770 . i j r \operatorname{cog} 20150084$

Cite this article as: Vijay A, Maran G, Koothan V. Impact of maternal obesity on obstetric outcome in a rural population in Pondicherry. Int J Reprod Contracept Obstet Gynecol 2015;4:740-4. 